\title{
Umbilical cord blood stem cells transplantation in a patient with severe progressive supranuclear palsy: a case report
}

\author{
Huiping Li ${ }^{\dagger}$, Fang Yuan ${ }^{\dagger}$, Yaming Du, Tao Pan, Wanxin Wen, Shaoxue Li, Lixin Wang* and Aili Lu*
}

\begin{abstract}
Background: Progressive supranuclear palsy is a neurodegenerative condition that worsens over time. Given the lack of targeted treatments, patients with severe progressive supranuclear palsy have very low life expectancy.

Case presentation: We present a case of a 61-year-old Chinese man with severe progressive supranuclear palsy and treated with umbilical cord blood stem cells transplantation. After the umbilical cord blood stem cells therapy, his neurologic symptoms stopped deteriorating, his muscle rigidity was mildly improved, and he remains alive for more than 8 years.

Conclusions: Umbilical cord blood stem cells transplantation may be an alternative therapy for patients with severe progressive supranuclear palsy.
\end{abstract}

Keywords: Progressive supranuclear palsy, Umbilical cord blood, Stem cells, Case report

\section{Introduction}

Progressive supranuclear palsy (PSP) is an adult-onset steady progressive neurodegenerative disease characterized by postural instability, ocular motor dysfunction, akinesia, and cognitive dysfunction [1]. PSP is associated with neurofibrillary tangles, neuronal loss, and gliosis, caused by the accumulation of microtubule-associated protein tau in the involved brain areas [2]. PSP lacks responses to dopaminergic drugs, and there are currently no targeted treatments for it. The prognosis of PSP is very poor: the median survival is only 7.3 years, and the survival of patients with severe PSP (PSP Rating Scale > $70)$ at 2 years is very rarely reported [3]

As a valuable donor source for allogeneic transplantation, umbilical cord blood (UCB) contains scalable pluripotent stem cells with the potential to form any human

*Correspondence: plawlx@gzucm.edu.cn; Luailitcm@gzucm.edu.cn

${ }^{\dagger}$ Huiping Li and Fang Yuan contributed equally to this work Department of Neurocritical Care, The Second Affiliated Hospital

of Guangzhou University of Chinese Medicine, Guangzhou 510120, China cell type in adults. Besides offering a renewable source of neural lineage [4], UCB is enriched with growth factors and cytokines that generate immunosuppressive and anti-inflammatory effects $[5,6]$. Therefore, umbilical cord blood stem cells (UCBSCs) transplantation may be an alternative therapy for treating PSP. Here we report the efficacy of transplantation of allogeneic UCBSCs for a patient with severe PSP.

\section{Case presentation}

A 61-year-old Chinese man who showed slow motion and speech at 53 years of age was admitted to our hospital in May 2012. At 54 years, gait instability, dysarthria, fine motor clumsiness, cognitive decline, and depression were observed. His difficulties in movement and postural stability then worsened gradually. At 56 years, he began to experience recurrent falls. At 58 years, he needed the aid of crutches when walking. At 59 years, he started to have incomprehensible speech, dysphagia, and double vision, and was confined to a wheelchair. Before his admission to our hospital, he had no treatments other original author(s) and the source, provide a link to the Creative Commons licence, and indicate if changes were made. The images or other third party material in this article are included in the article's Creative Commons licence, unless indicated otherwise in a credit line to the material. If material is not included in the article's Creative Commons licence and your intended use is not permitted by statutory regulation or exceeds the permitted use, you will need to obtain permission directly from the copyright holder. To view a copy of this licence, visit http://creativecommons.org/licenses/by/4.0/. The Creative Commons Public Domain Dedication waiver (http://creativeco mmons.org/publicdomain/zero/1.0/) applies to the data made available in this article, unless otherwise stated in a credit line to the data. 


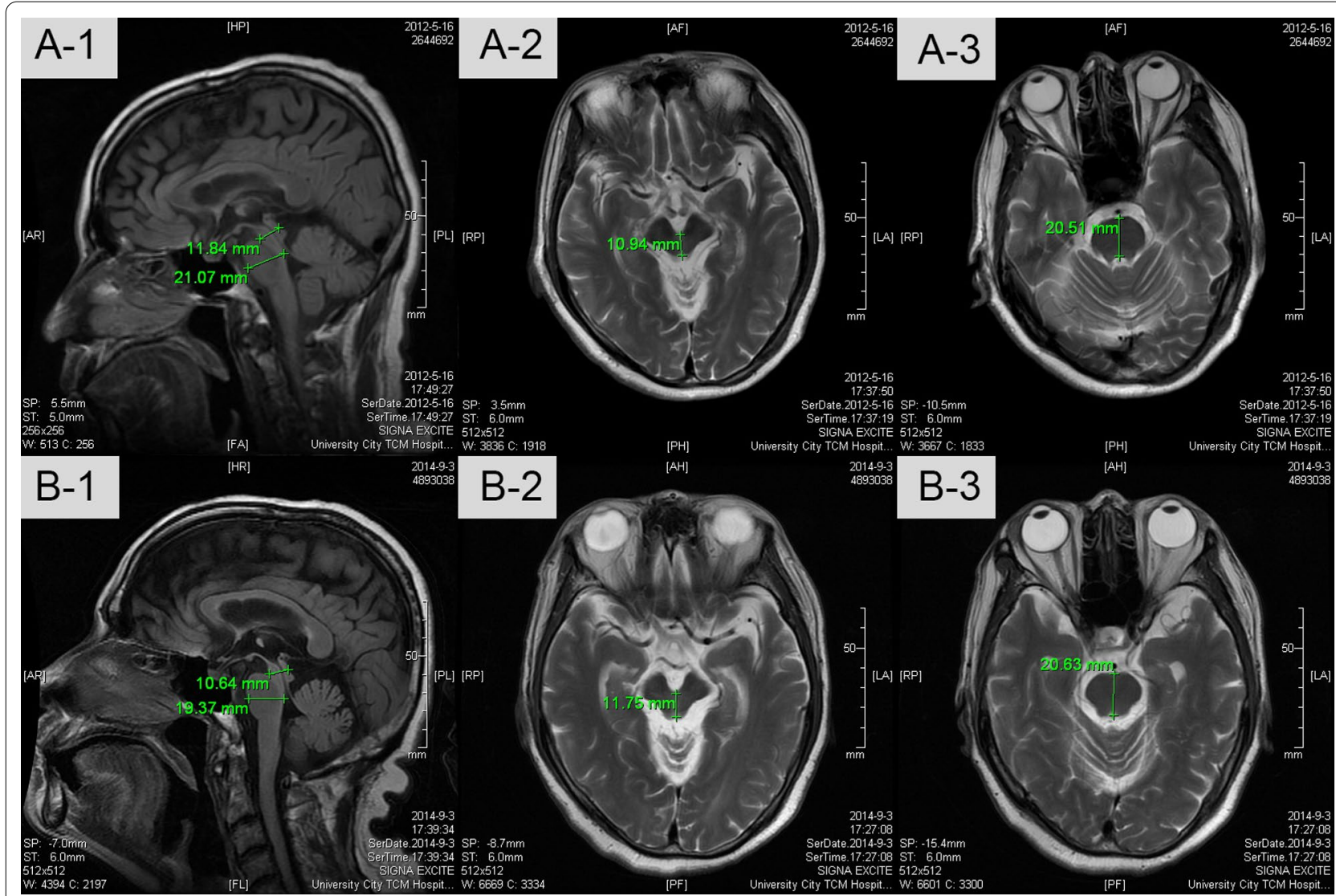

Fig. 1 Brain MRI before and after umbilical cord blood stem cells therapy. A 1-3: MRI in May 2012. B 1-3: MRI in September 2014. The atrophy of pons and mesencephalon did not deteriorate 2 years after umbilical cord blood stem cells therapy

than irregular vitamin intake. His medical and family histories were unremarkable.

Neurological examination revealed cognitive decline, decreased spontaneous speech, masked face, oculomotor abnormalities, muscle rigidity, ataxia, dysarthria, and dysphagia. His cognitive impairment included apathy, marked slowing of cognition, decreased verbal fluency, and frontal release signs. His ocular movements were slow and limited in vertical direction. Muscle strength was mildly decreased in all four limbs (4/5). His limbs and axial muscles were rigid. His rapid alternating movements were clumsy and finger-to-nose and heel-to-shin movements were awkward. Resting and postural tremors in limbs were not observed. Superficial and deep sensations were intact. Deep tendon reflexes in all limbs were brisk. Sucking reflex and bilateral palmomental reflexes were present, and bilateral Babinski and Chadock signs were positive. His symptoms were not responsive to levodopa. His laboratory tests during hospitalization were unremarkable. His brain magnetic resonance imaging (MRI) scan (3.0T) suggested mild ventricle enlargement, marked atrophy of mesencephalon and cerebellum, and "Hummingbird sign" in the mesencephalon (Fig. 1).

According to clinical diagnostic criteria of PSP from the Movement Disorder Society [1], this patient was diagnosed with probable PSP with Richardson's syndrome (prob. PSP-RS). His PSP rating scale was 73 on admission [3]. After the approval of the Ethics Committee of Guangdong Provincial Hospital of Chinese Medicine and the acquisition of patient's informed consent, this patient received the transplantation of UCBSCs.

\section{Preparation of UCBSCs}

We followed previous preparation protocol of allogeneic UCBSCs (Fig. 2) [7]. The general preparation procedure is shown in Fig. 2. UCB $(100 \mathrm{ml})$ was collected from healthy unrelated donors [8]. To ensure the safety of UCBSCs, pathogen detection was performed to avoid potential infection, including hepatitis $B$ surface antigen (HBsAg) anti-hepatitis $\mathrm{C}$ virus (HCV), anti-human immunodeficiency virus (HIV), rapid plasma reagin (RPR), and TORCH five items. Mononuclear cells were then collected. The stem cells with a concentration 


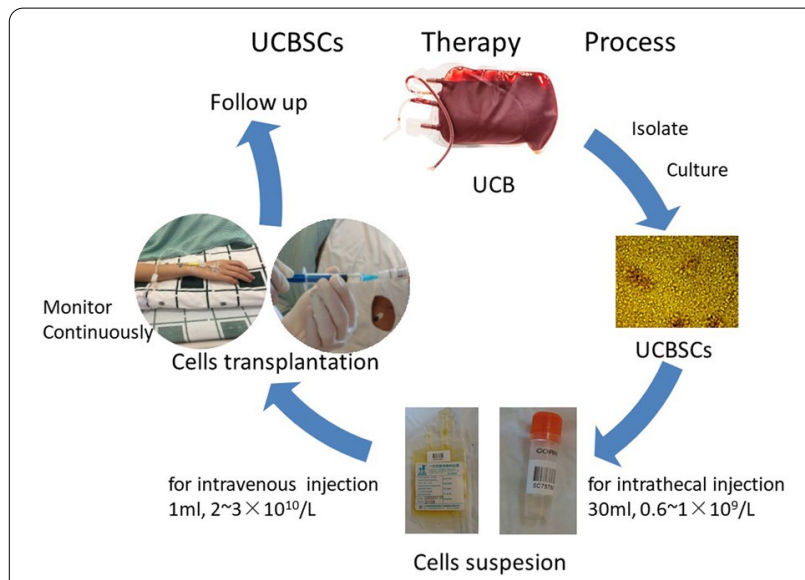

Fig. 2 Umbilical cord blood stem cells therapy flow chart. UCB umbilical cord blood, UCBSCs umbilical cord blood stem cells

of $2-3 \times 10^{10} / \mathrm{L}$ were kept in $1 \mathrm{ml}$ nutrient solution in a small bottle for intrathecal injection. The cells with $0.6-1.0 \times 10^{9} / \mathrm{L}$ were kept in $30 \mathrm{ml}$ nutrient solution in a blood bag for intravenous infusion. The stem cells were counted by whole blood analyzer syxmex100i: cell quantity of 1 unit $\geq 2-3 \times 10^{7}$ cells. Cell viability was detected by COUNTSTAR Cell Counter: standard viability $\geq 90 \%$. CD34+ cells were determined by flow cytometry (BD FACSCalibur), 1.0-2.0\% CD34+ cells were required. The packed cells were placed upright in a vaccine ice box $\left(2-8{ }^{\circ} \mathrm{C}\right)$. The cells were delivered to patients no more than 12 hours after preparation.

\section{UCBSCs therapy}

The whole treatment included two intravenous infusions (30 ml, $2-3 \times 10^{7}$ cells, per time) and four intrathecal injections ( $1 \mathrm{ml}, 2-3 \times 10^{7}$ cells, per time). The first and last injections were intravenous infusions, and the rest were intrathecal injections. The interval between every two injections was 3 days. Adverse events were closely monitored during and after the treatment.

\section{Outcome}

This case was followed up via clinical interviews and phone calls by an experienced clinician. Three months after UCBSCs therapy, rigidity of his limbs and neck was mildly alleviated (Fig. 3). Six months after UCBSCs therapy, tube feeding was not required. The condition of this patient was stable over the next 2 years. Three years after UCBSCs therapy, the patient required tube feeding again, but the rigidity of limbs and neck was still better compared with the baseline level. All the other neurological deficits did not deteriorate until the last follow-up (through 8 years in total). No deterioration of cerebral lesions was found in his brain MRI 2 years after the treatment (Fig. 1). During the follow-up, no adverse event was observed. The progression of PSP seemed to cease after the UCBSCs therapy.

\section{Discussion}

PSP is a progressive neurological disorder without effective treatments. Here, we presented a severe PSP case treated with UCBSCs. This patient had a PSP rating score of 73 on admission, and his score reduced by two to three points during the follow-up of 8 years. Previous studies indicated that PSP rating score in patients with PSP increases at a mean rate of 11-18 points per year, and 2-year survival was rarely reported in patients with PSP rating score over $70[3,9]$. Our case suggested that UCBSCs transplantation might delay the progression of PSP.

Mesenchymal stem cells (MSCs) from UCB can differentiate into endothelial, epithelial, hematopoietic, and potential neural progenitor cells, and have been used to treat many neurodegenerative diseases, such as Alzheimer's disease, Parkinson's disease, amyotrophic lateral sclerosis, and so on [10-12]. MSCs were also demonstrated to reduce activated macrophages/microglia, attenuate reactive astrocytes, and increase white matter sparing [13-15]. In our case of severe PSP, UCBSCs transplantation delayed the disease progression, probably via the effects of neurogenesis, neuroprotection, and immunomodulation.

Bone marrow, adipose tissues, and umbilical cord blood are the most common origins of MSCs. Although MSCs are abundant in bone marrow, they are obtained via an invasive procedure that raises some ethical issues. Besides, both the proliferation and differentiation capacity of bone marrow-derived MSCs decrease with age. Previously, a case study reported that the treatment of autologous adipose tissue-derived MSCs safely delayed the progression of PSP [16]. The proliferation rate of adipose-derived MSCs is lower than UCB-derived MSCs [17]. The secretion levels of transforming growth factor- $\beta 1$ (TGF- $\beta 1$ ) and prostaglandin E2 $\left(\mathrm{PGE}_{2}\right)$ in adipose-derived MSCs are also lower than in UCB-derived MSCs [17]. TGF- $\beta 1$ exerts pleiotropic effects on the suppression of $\mathrm{T}$ cells and was suggested to improve the cell survival of transplanted MSCs [18]. PGE2 was also reported to enhance the therapeutic effect of MSCs in traumatic brain injury [19].

The UCB stem cells are less mature and immunogenic, and they cause less graft versus host disease (GVHD), so a perfect human leukocyte antigen (HLA) match is not required for allogeneic transplantation of UCB [20]. Our previous study also found no serious adverse events associated with UCBSCs therapy in 47 patients with cerebral palsy [8]. In this study, we chose two different routes to administer UCBSCs: intrathecal 


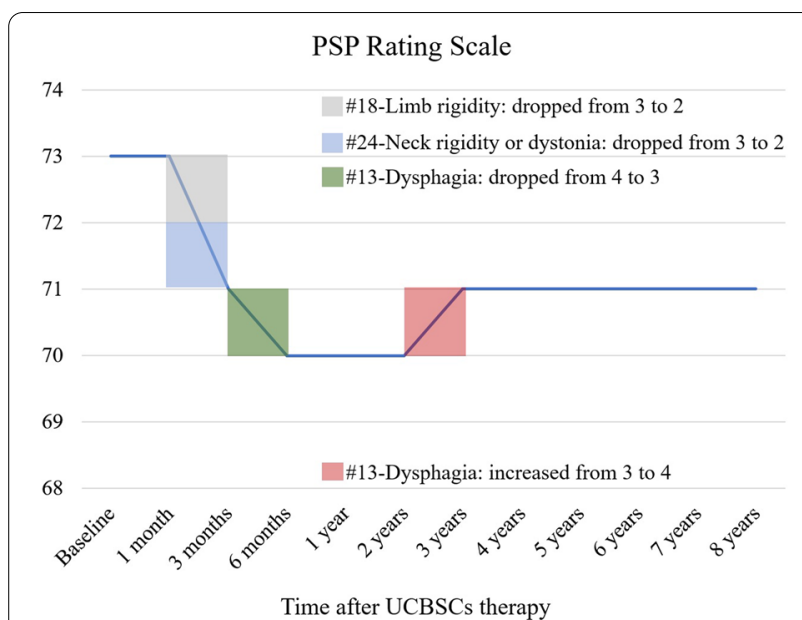

Fig. 3 Progressive supranuclear palsy rating scale over 8 years: 73 points at baseline: \#1-Withdrawal: 2; \#2-Irritability: 2; \#3-Dysphagia for solids: 4; \#4-Using knife and fork, buttoning clothes, washing hands and face: 4; \#5-Falls: 3; \#6-Urinary incontinence: 3; \#7-Sleep difficulty: 0; \#8-Disorientation: 3; \#9-Bradyphrenia: 3; \#10-Emotional incontinence: 2; \#11-Grasping/imitative/utilizing behavior: 3; \#12-Dysarthria: 4; \#13-Dysphagia: 4; \#14-Voluntary upward command movement: 3; \#15-Voluntary downward command movement: 1; \#16-Voluntary left and right command movement: 1; \#17-Eyelid dysfunction: 1; \#18-Limb rigidity: 3; \#19-Limb dystonia: 4; \#20-Finger tapping: 2; \#21-Toe tapping: 2; \#22-Apraxia of hand movement: 2; \#23-Tremor in any part: 0; \#24-Neck rigidity or dystonia: 3; \#25-Arising from chair: 3; \#26-Gait: 4; \#27-Postural stability: 4; \#28-Sitting down: 3

and intravenous. UCBSCs can directly reach the central nervous system by the intrathecal route, and a higher dosage of UCBSCs can be administered by the intravenous route.

The PSP rating score of this patient increased by one point in the third year after UCBSCs transplantation owing to the progressive nature of PSP. However, it remained the same until the last follow-up, and it is still lower than the baseline score. Whether repeated transplantation of UCBSCs will exert better and longer therapeutic effects needs to be explored further. This is only one case report, and randomized controlled trials are needed in the future to validate the therapeutic effect of UCBSCs transplantation in PSP and to determine the optimal dosage, administration route, and treatment duration.

\section{Conclusions}

We presented a severe PSP case treated with UCBSCs. In this case, the UCBSCs therapy mitigated muscle rigidity, prevented the atrophy of pons and mesencephalon, and hindered the deterioration of neurologic symptoms. UCBSCs transplantation may be an alternative therapy for patients with severe PSP.

\section{Abbreviations}

HCV: Hepatitis C virus; HBsAg: Hepatitis B surface antigen; HIV: Human immunodeficiency virus; PSP: Progressive supranuclear palsy; RPR: Rapid plasma reagin; RS: Richardson's syndrome; UCB: Umbilical cord blood; UCBSCs: Umbilical cord blood stem cells.

\section{Acknowledgements \\ Not applicable.}

\section{Authors' contributions}

FY, HL, YD, and TP gathered patient data regarding clinical presentation. FY and $\mathrm{AL}$ drafted the initial manuscript. TP, WW, and SL performed physical examination and follow-up. AL prepared umbilical cord blood stem cells (UCBSCs) and performed UCBSCs therapy. FY, HL, YD, and LW reviewed and revised the manuscript. SL and LW obtained funding. All authors read and approved the final manuscript.

\section{Funding}

This research was funded by Project of Administration of Traditional Chinese Medicine of Guangdong Province of China (No.20211157).

\section{Availability of data and materials}

Not applicable.

\section{Declarations}

\section{Ethics approval and consent to participate}

Waived. The Second Affiliated Hospital of Guangzhou University of Chinese Medicine was approved to perform umbilical cord blood stem cells therapy by Traditional Chinese Medicine Bureau of Guangdong Province ([2008] 189). Written informed consent were obtained from the proxy of the patient for UCBSCs therapy.

\section{Consent for publication}

Written informed consent was obtained from the patient for publication of this case report and any accompanying images. A copy of the written consent is available for review by the Editor-in-Chief of this journal.

\section{Competing interests}

The authors declare that they have no competing interests.

Received: 21 May 2020 Accepted: 1 October 2021

Published online: 29 November 2021

\section{References}

1. Hoglinger GU, Respondek G, Stamelou M, et al. Clinical diagnosis of progressive supranuclear palsy: the movement disorder society criteria. Mov Disord. 2017;32(6):853-64.

2. Giagkou N, Hoglinger GU, Stamelou M. Progressive supranuclear palsy. Int Rev Neurobiol. 2019;149:49-86.

3. Golbe LI, Ohman-Strickland PA. A clinical rating scale for progressive supranuclear palsy. Brain. 2007;130(Pt 6):1552-65.

4. Tao Y, Zhang S-C. Neural subtype specification from human pluripotent stem cells. Cell Stem Cell. 2016;19(5):573-86.

5. Shiao ML, Yuan C, Crane AT, et al. Immunomodulation with human umbilical cord blood stem cells ameliorates ischemic brain injury-a brain transcriptome profiling analysis. Cell Transplant. 2019;28(7):864-73.

6. Schreurs M, Suttorp CM, Mutsaers HAM, et al. Tissue engineering strategies combining molecular targets against inflammation and fibrosis, and umbilical cord blood stem cells to improve hampered muscle and skin regeneration following cleft repair. Med Res Rev. 2020;40(1):9-26.

7. Yang WZ, Zhang Y, Wu F, et al. Safety evaluation of allogeneic umbilical cord blood mononuclear cell therapy for degenerative conditions. J Transl Med. 2010;8:75. 
8. Feng M, Lu A, Gao H, et al. Safety of allogeneic umbilical cord blood stem cells therapy in patients with severe cerebral palsy: a retrospective study. Stem Cells Int. 2015;2015:325652.

9. Whitwell JL, Xu J, Mandrekar JN, Gunter JL, Jack CR Jr, Josephs KA. Rates of brain atrophy and clinical decline over 6 and 12-month intervals in PSP: determining sample size for treatment trials. Parkinsonism Relat Disord. 2012;18(3):252-6.

10. Achyut BR, Varma NR, Arbab AS. Application of umbilical cord blood derived stem cells in diseases of the nervous system. J Stem Cell Res Ther. 2014. https://doi.org/10.4172/2157-7633.1000202.

11. Batsali AK, Kastrinaki MC, Papadaki AH, et al. Mesenchymal stem cells derived from Wharton's Jelly of the umbilical cord biological properties and emerging clinical applications. Curr Stem Cell Res Ther. 2013;8(2):144-55.

12. Han F, Paul Lu. Introduction for stem cell based therapy for neurodegenerative diseases. Adv Exp Med Biol. 2020;1266:1-8.

13. Abrams MB, Dominguez C, Pernold K, et al. Multipotent mesenchymal stromal cells attenuate chronic inflammation and injury-induced sensitivity to mechanical stimuli in experimental spinal cord injury. Restor Neurol Neurosci. 2009;27(4):307-21.

14. Osaka M, Honmou O, Murakami T, et al. Intravenous administration of mesenchymal stem cells derived from bone marrow after contusive spinal cord injury improves functional outcome. Brain Res. 2010;1343:226-35.

15. Ribeiro TB, Duarte AS, Longhini AL, et al. Neuroprotection and immunomodulation by xenografted human mesenchymal stem cells following spinal cord ventral root avulsion. Sci Rep. 2015;5:16167.

16. Choi SW, Park KB, Woo SK, et al. Treatment of progressive supranuclear palsy with autologous adipose tissue-derived mesenchymal stem cells a case report. J Med Case Rep. 2014;8:87.

17. Nakao M, Inanaga D, Nagase K, Kanazawa $\mathrm{H}$. Characteristic differences of cell sheets composed of mesenchymal stem cells with different tissue origins. Regen Ther. 2019;11:34-40,

18. Niu J, Yue W, Le-Le Z, et al. Mesenchymal stem cells inhibit T cell activation by releasing TGF- $\beta 1$ from TGF- $\beta 1$ GARP complex. Oncotarget. 2017:8(59):99784-800

19. Kota DJ, Prabhakara KS, Toledano-Furman N, et al. Prostaglandin E2 indicates therapeutic efficacy of mesenchymal stem cells in experimental traumatic brain injury. Stem Cells. 2017;35(5):1416-30.

20. Newcomb JD, Sanberg PR, Klasko SK, et al. Umbilical cord blood research current and future perspectives. Cell Transplant. 2007;16(2):151-8.

\section{Publisher's Note}

Springer Nature remains neutral with regard to jurisdictional claims in published maps and institutional affiliations.

Ready to submit your research? Choose BMC and benefit from:

- fast, convenient online submission

- thorough peer review by experienced researchers in your field

- rapid publication on acceptance

- support for research data, including large and complex data types

- gold Open Access which fosters wider collaboration and increased citations

- maximum visibility for your research: over 100M website views per year

At BMC, research is always in progress.

Learn more biomedcentral.com/submissions 